Voix et Images

voixetimages

\title{
Table des matières du volume XIV
}

Volume 14, numéro 3 (42), printemps 1989

Gabrielle Roy

URI : https://id.erudit.org/iderudit/200808ar

DOI : https://doi.org/10.7202/200808ar

Aller au sommaire du numéro

Éditeur(s)

Université du Québec à Montréal

ISSN

0318-9201 (imprimé)

1705-933X (numérique)

Découvrir la revue

Citer ce document

(1989). Table des matières du volume XIV. Voix et Images, 14(3), 527-527.

https://doi.org/10.7202/200808ar

Ce document est protégé par la loi sur le droit d'auteur. L'utilisation des services d'Érudit (y compris la reproduction) est assujettie à sa politique d'utilisation que vous pouvez consulter en ligne.

https://apropos.erudit.org/fr/usagers/politique-dutilisation/
Cet article est diffusé et préservé par Érudit.

Érudit est un consortium interuniversitaire sans but lucratif composé de l’Université de Montréal, l'Université Laval et l'Université du Québec à Montréal. Il a pour mission la promotion et la valorisation de la recherche. https://www.erudit.org/fr/ 


\section{TABLE DES MATIÉRES DU VOLUME XIV}

ANDRÈS, Bernard, «Histoire d'histoires litueraires», 2, p. 325-329.

BIRON, Michel, \&Idéologie et pósie: un poème de Paul-Marie Lapointes, 1, p. 90-118.

BOURBONNAIS, Nicole, eGabrielle Roy: la représentation du corps féminin», 1, p. 72-89; *Gabrielle Roy et Margaret Laurence: devx chemins, une recherche de Terrance Hugues», 2, p. 330-333.

BRAULT, Jacques, *Tonalités lointaines (sur l'ecriture intimiste de Gabrielle Roy)», 3, p. 387-398.

BROCHU,, André, «Langages en libertés, 1, p. 135-145; «Temps et lieux du poéme», 2, p. 345-352; aLe schème organisateur chez Gabrielle Roy», 3, p. 414-422; *La critique est faillible», 3, p. 513-521.

BRUNET, Manon, «Anonymat et pseudonymat au XIXe siècle: l'envers et l'endroit de pratiques institutionnelless, 2, p. 168-182.

CHADBOURNE, Richard M., «La part prophétique dans les premiers romans de Gabrielle Roy», 3, p. $399-407$.

CHAMBERLAND, Paul, *Transporter la mer dans ses main8x, 2, p. 336-338.

DUPRÉ, Louise, \&Une poésie de l'effraction $x, 1$, p. 24-30.

FILTEAU, Claude, «Rhétorique et philosophie politique. De la cité antique à l'idée de patrie chez Jean Charbonneau et Alfred DesRochers», 2, p. 250-268.

GALLAYS, François, «Modemité/Postmodemité: problème taxinomique? combat de légitimité? crise de culture?x, 3, p. 504-507.

GIGUËRE, Richard, «Un mouvement de prise de parole: les petits éditeurs de poésie des années 50 et 60 au Québeco, 2, p. 211-225.

GIRARD, Hélène, *Bibliographie de France Théorets, 1, p. 57-71.

GOULD, Karen, «L'écrivaine/Aa putain ou le territoire de l'inscription féminine chez France Thérets, 1. . 31-38.

GRISẾ, Yolande, «La thématique de la forêt dans deux nomans ontarois», 2, p. 269-280.

HAREL, Simon, *I a tentation cosmopolite», 2, p. 281-293.

HÉBERT, Pierre, *Les plaisirs de lire», 1, p. 130-135; *De l'effet "premier roman" à celui de Summerhill: cette libenté si difficile, si nécessaire...», 2, p. 339-344; *Les fruits de 1'hivem, 3, p. 508-512.

HERDEN, Marin, aLe monologue interieur dans The Sound and the Fury de William Faulkner et le Sourd dans la ville de Marie-Claire Blais», 3, p. 483-496.

HOUDE, Roland et Jacques BEAUDRY, «Expression et expansion: l'offensive littéraire française de l'après-guerre au Québecs, 2, p. 237-248.

LEJEUNE, Claire, \&Faire arriver ce qui n'existe pas encores, 1, p. 50-56.

MAJOR, Robent, «Un goôt d'amertume, un parfum de désenchantement... et leur antidote», 1, p. 120 123; «Prises de parole», 2, p. 322-325; «Papiers collés, papiers à lires, 3, p. 498-503.

MARCOTTE, Gilles, «Bonheur d' occasion et le "grand realisme" $s, 3$, p. 408-413.

MARTIN, Claude et Vincent NADEAU, «Auteurs et entreprises dans l'édition linéraire contemporaine au Québec», 2, p. 226-236.

MEADWELL, Kenneth W., «Ludisme at clichés dans l'Avalée des avalés de Réjean Ducharmes, 2 , p. 294-300.

MICHAUD, Gineus, «Mille plateaux: topographie et typographie d'un quartiens, 3, p. 462-482.

MICHON, Jacques, «Presentation», 2, p.166-167; aLes Editions de l'Arbre, 1941-1948\%, 2, p. 194 210.

PELLETIER, Jacques, xLe critique comme createurs, 1, p. 127-130.

PERRON, Paul, La création de Gérard Bessette de Réjean Robidoux», 1, p. 125-127.

POTVIN, Claudine, \&L'esthétique du détail dans Nous parlerons comme on écrito, 1, p. 39-49.

REISMAN BABBY, Ellen, «Â la recherche du sens: De quoi $t^{\prime}$ ennuies-tu, Eveline?», 3, p. 423-432.

RICARD, Francois, «Présentation», 3, p. 374; «Note bibliographiques, 3, p. 375; «La biographie de Gabrielle Roy: problèmes et hypothèsesx, 3, p. 453-460.

ROBERT, Lucie, \&Le Canada imaginaire des Français», 1, p. 123-125; *Heureux anniversairel», 1 , p. 145-148; *Avant-propos», 2, p. 164; *Le livre ef l'Etats, 2, p. 183-193; *Constellation classiques, 2, p. 353-356, «Avant-propos», 3, p. 372; «Ecrire le thêâtre», 3, p. 521-524.

ROBIDOUX, Réjean, \&Gabrielle Roy: la somme de l'cuvre», 3, p. 376-379.

SHEK, Ben-Z, \&De quelques influences possibles sur la vision du monde de Gabrielle Roy: George Wilkinson et Henni Girards, 3, p. 437-452.

SIROIS, Antoine, *De l'idéologie au mythe: la nature chez Gabrielle Roym, 3, p. 380-386.

SMART, Patricia, «France Théoret: narratice de la subjectivité. Présentation», 1, p. 6-8; «Entrevue avec France Theorets, 1, p. 11-23.

SOCKEN, Paul G., *L'enchantement dans la détresse: l'irréconciliable teconcilié chez Gabrielle Roy», 3, p. 433-436.

THEORET, France, \&Le tweed anglais», 1, p. 8-11.

TREMBLAY, Danielle, *Perspectives contemporaines sur la chanson francophone», 2, p. 333-336.

WALL, Anthony, «Prisormiers dans ce trou, ce Trou de mémoire», 2, p. 301-321. 